\title{
Drug Firm Sponsorship of College Activities
}

The following guidelines on sponsorship by drug firms of College activities have been drawn up and approved by Council:

1. Whenever possible money should be used to improve the quality of scientific activities rather than the level of hospitality and social events, e.g. by paying for speakers' expenses, hire of premises, circulation of notices, provision of visual aids, etc.

2. The approach to a drug firm or firms for support should be by an Officer of the College or of one of its Divisions. Sections, Groups or Committees (e.g. Collegiate Trainees, Psychiatric Tutors etc.)

3. Whenever possible the creation of separate bank accounts should be avoided and the Treasurer's office involved in receiving and issuing cheques. A separate 'ledger entry' can be kept for each Division, Section, etc. and a figure produced at the end of each year to indicate the total amount of sponsorship involved.

4. Appropriate acknowledgment of the source of sponsorship should appear on the notice of any meeting (or social function) so sponsored.

5. An advertising display can be set up in association with a meeting subject to the approval of the 'owners' of the building concerned. Where more than one company has been approached this should be made clear to the various drug firms concerned. Some companies prefer to be the sole sponsors of a meeting and may be willing to make a larger contribution if this is made clear.

6. Where meetings are held in hospitals the choice of speakers and the decision whether or not to use private caterers should remain under the control of the doctor organizing the meeting. Valuable guidelines on this and other aspects are contained in the 'Report of the Working Party on the Role of the Pharmaceutical Industry in Postgraduate Medical Education' published by and obtainable from the Medico-Pharmaceutical Forum, 1 Wimpole Street, London WIM 8AE (cost £3.00).

7. Where a drug firm organizes its own meeting and invites speakers, defrays participants' expenses or provides hospitality the College's name should not be used or acknowledged.

8. The help of the pharmaceutical industry in supporting medical educational activities is understood and appreciated, but the overriding consideration where the College is concerned is that the choice of the scientific programme and of the level of hospitality and advertising should be controlled by College officials.

\section{COLLEGE PRIZES}

\section{Bronze Medal and Research Prize}

It has been decided that the Bronze Medal, which was established at the Annual Meeting held on 2 August 1882, will be awarded to the winner of the Research Prize. The 1979 Research Prize was won by Dr J. Chick, who will receive the Bronze Medal.

\section{Laughlin Prize}

The Laughlin Prize, value $£ 50$ will be awarded twice a year in the Spring and Autumn to the candidate who obtains the highest marks and the best recommendation from the examiners in the Membership Examination.

\section{ECT SUR VEY}

There has been an encouraging response to the questionnaire. If you have not yet returned yours to the Research Office, please do so, without waiting until you have completed the three-month prospective study, and even if you think the questionnaire does not really apply to you.
If you have reservations about the enquiry will you let me know, by letter or a telephone call to 01-235-0730?

John PIPpard Research Office 